\title{
Een reële optieanalyse van het gelijktijdig ontwikkelen van twee productstandaarden
}

Drs. L.J.O. Lint en Drs. H.P.G. Pennings

\section{Introductie}

Dixit en Pindyck (1994) beargumenteren dat de traditionele Netto Contante Waarde-methode (NPV) bij investeringsbeslissingen alleen dan kan worden toegepast wanneer de investering het karakter heeft van een nu-of-nooit beslissing of wanneer de beslissing omkeerbalar is, hetgeen betekent dat de investeringsuitgaven volledig en onvoorwaardelijk kunnen worden teruggekregen. In de praktijk zijn investeringen in de regel onomkeerbaar. Een initiële investering die de mogelijkheid creëert tot vervolginvesteringen, waarbij het management over de tlexibiliteit beschikt om op een later lijdstip al dan niet tot die vervolginvesteringen over te gaan, heeft in dit verband dan ook een asymmetrische payoff: verlies is gelimiteerd tot de initiële investering, terwijl de opbrengst ongelimiteerd is. Het grote voordeel van de optieanalyse in tegenstelling tot de NPV-analyse is dat deze asymmetrische payoff expliciet deel uitmaakı van de waardering. Binnen deze gedachtegang zijn Kester (1984) en Myers (1984) - en in MAB Kemna (1988) - bekende initiators met betrekking tot reële optieanalyse en financiële besluitvorming vanuit een managementperspectief. Voor recente besprekingen omtrent de tekortkomingen van de NPV-methode en de bijdrage van de reële optieanalyse in dit verband verwijzen wij naar Smit (1996) en Trigeorgis (1996).

Drs. L.J.O. Lint en Drs. H.P.G. Pennings zijn als STW Research Fellows verbonden aan de Erasmus Universiteit Rotterdam. Zij zijn Stewart C. Myers van het Massachusetts Institute of Technology erkentelijk voor enkele waardevolle suggesties. De studie is verricht met financiële ondersteuning van de Stichting voor de Technische Wetenschappen.
Net als bij financiële opties geldt hierbij dat hoe groter de onzekerheid rond markt- en economische omstandigheden is, des te groter de waarde van strategische flexibiliteit zal zijn. Tevens geldı dat hoe langer de periode tot het uitoefenmoment van de optie is, des te groter het potentieel zal zijn voor omstandigheden die voor de uitoefening van de optie gunstig zijn. Echter, de keuze van het juiste tijdstip van afronding van het project is van significant belang voor het succes, omdat de noodzaak zich voordoet om initiële investeringen voor een bepaalde datum te realiseren in verband met het opdoen van noodzakelijke technologische ervaring en om de concurrentie te snel af te zijn. Het uitoefenen van de optie na deze datum leidt tot verlies aan pioniersvoordelen en toekomstig marktaandeel, omdat zulke voordelen geschapen worden tijdens de eerste fasen van de productlevenscyclus. Echter. de doorlooptijd van het voltooien van de $R \& D$ van nieuwe producten creëert een minimale uitoefentijd van de optie, omdat uitoefenen van de optie voor deze datum een grote kans op een technologisch falen in de markt impliceert door onvoldoende geteste producten. Opties in sterk concurrerende markten hebben derhalve een typisch Europees karakter. Deze opties kumnen niet worden uitgeoefend voor het uitoefenmoment van de optie. Wij beschouwen het optimale tijdstip van onomkeerbare vervolginvesteringen dan ook als het moment waarop de R\&Dfasen zijn voltooid.

Wanneer slechts één nieuwe en verbeterde productstandalard wordt ontwikkeld dan kunnen bedrijven overstappen van de bestaande op de nieuwe standaard. De huidige bestissing om al dan niet technologie te ontwikkelen voor de nieuwe standaard hangt af van de optiewaarde om in de toekomst de contante waarde van de huidige 
standaard om te ruilen voor de contante waarde van de nieuw ontwikkelde standaard. De waarde van deze optie hangt vervolgens af van de verwachte opbrengsten van de nieuwe standaard en de verwachte opbrengsten van de oude standaard. Indien de verwachte opbrengsten van de nieuwe standaard de verwachte opbrengsten van de oude standaard overtreffen. is de optiewaarde hoog en is het de moeite waard on technologie voor de nieuwe standaard te ontwikkelen. Een dergelijke optie om het ene risicovolle actief te vervangen door een ander is uitgewerkt door Margrabe (1978).

Wanneer echter twee concurrerende standaarden ontluiken dan worden de betrokken ondernemingen geconfronteerd met de beslissing om ofwel technologie voor beide standaarden te ontwikkelen en de standaard te kiezen die uiteindelijk domineert en die door de branche gesteund wordt danwel technologie voor een van beide standaarden te ontwikkelen, in casu degene die de hoogste netto-optiewaarde heeft. Om dit dilemma van een praktische oplossing te voorzien, bouwen wij voort op het model van Stulz (1982) voor de waarde van de optie op het maximum van twee risicodragende activa. Ons model waardeert de flexibiliteit die verworven wordt door twee productstandaarden te ontwikkelen die verschillend zijn qua productkarakteristieken in plaats van het ontwikkelen van uitsluitend één productstandaard. Johnson (1987) en Sanchez (1991) bieden aanvullende modellen voor een onderneming die de mogelijkheid heeft uit meer dan twee productstandaarden te kiezen. Het vervolg van dit artikel bestaat uit de toepassing van het in de appendix gedefinieerde model op een standaardisatievraagstuk bij het Philipsconcern.

\section{Beschrijving praktijktoepassing}

Het Philipsconcern opereert in een complexe, wereldwijde markt. Een wereldwijde standaardisatie is hierdoor noodzakelijk. Concurrentie vindt plaats op hoog technologisch niveau en is uitgesproken agressief met vele Aziatische concurrenten die belangrijke marktaandelen proberen te verwerven. Vanuit een gestileerd perspectief kan de markt voor consumentenelektronica gezien worden als een technologische push markt, waarin de vraagzijde van de markt wordt gemanipuleerd door de aanbieders door middel van een continue productinnovatie. De industriële bedrijven in deze markt kunnen worden beschouwd als de machtige spelers, omdat de individuele consument niet over de organisatorische achtergrond beschikt om een beïnvloedende rol te spelen in de marktontwikkeling. Echter, in het proces van de acceptatie van een definitieve productstandaard, speelt de software industrie (videofilmproducenten en -distributeurs) een doorslaggevende rol. Indien zij een nieuwe standaard niet ondersteunen, blijven de consumenten achter met apparatuur waarop verkrijgbare films niet afspeelbaar zijn.

Om het gestileerde beeld verder te detailleren kan de markttoetreding worden beschouwd als zijnde afgeschermd door de grote. machtige multinationals die over voldoende technologische kennis beschikken om concurrerend te blijven en die daardoor zelden worden bedreigd door buitenstaanders van de markt. De betrokken ondernemingen kunnen worden beschouwd vanuit het perspectief dat zij in massahoeveelheden producten op de markt brengen met vrijwel gelijke gebruiksfuncties, waardoor het marktaanbod de marktvraag overtreft. hetgeen resulteert in snel dalende prijzen direct na introductie van nieuwe producten (penetratieprijsstrategieën). Snelle productdifferentiatie wordt eveneens toegepast voor dit doel, met name ook Sony heeft een reputatie op dit gebied (Sanderson en Uzumeri, 1995).

$\mathrm{Wij}$ hebben een investeringsproject geanalyseerd betreffende de ontwikkeling van productietechnologieën voor de videorecordermarkt. Het kader dat hiertoe is uitgewerkt is met name geschikt wanneer het gedurende de eerste fasen van het R\&D-traject onzeker is, welk prototype de uiteindelijke standaard wordt en wanneer een verkeerde voorspelling van de winnende standaard belangrijke gevolgen heeft voor toekomstige marktaandelen. Door toepassing van dit kader kunnen de mogelijkheden worden geanalyseerd van uitstel van het tijdstip waarop onomkeerbare vervolginvesteringen moeten worden gedaan. Hierdoor neemt de kans dat de juiste standaard wordt ontwikkeld aanmerkelijk toe.

Opgemerkt wordt dat bij onze uitwerking de weergegeven standpunten met betrekking tot het ontwikkelen van nieuwe technologieën en productstandaarden uitsluitend onze eigen visie weerspiegelen en dat deze standpunten niet noodzakelijkerwijs overeenkomen met voormalige of huidige officiële standpunten van het Philipsconcern op dit terrein. De financiële gegevens zijn uitsluitend bedoeld ter illustratie en komen niet noodzakelijkerwijs overeen met de werkelijkheid. De be- 
schrijving van de casuspositie staat los van meer recente beslissingen rond productstandaarden voor digitale video, zoals de met Sony ontwikkelde MMCD. Recent zijn twee standaarden voor digitale video ontwikkeld: een in samenwerking tussen Philips en Sony en een andere door cen consortium bestaande uit Toshiba en TimeWarner. Deze strijd is geëindigd met een overeenkomst tussen beide partijen over een uniforme standaard. In deze strijd speelde het management van de betrokken ondernemingen een doorslaggevende rol. Voor een analyse van deze strijd moet dan ook gebruik gemaakı worden van speltheoretische inzichten. 7ic Lint en Pennings ( 1998 ).

\section{Probleemanalyse}

Tijdens de analyselase hebben wij de belangrijke trends in miniaturisatie en digitalisaltie bestudeerd. alsmede de noodzaak van een uniforme standaard vanwege een wereldwijde productintroductie en de noodzakelijke massaproductic. Consumenten blijken een voorkeur te hebben voor handzame en compacte apparatuur (miniaturisa(ie). Digitale apparaltuur biedt meer mogelijkheden en een snellere beeldverwerking. Daarnaast is aandach geschonken aan de invloed valn softwarebedrijven die zeer belangrijk zijn in het aceeptatieproces van een nieuwe standaard. Als doelstellingen van Philips kunnen in dit verband worden gezien het spelen van een vooraanstiande rol in de ontwikkeling van een nieuwe wereldwijde standaard in videotechnologieën. het voorkomen van het afhankelijk worden van concurrenten en het voorkomen van een late toetreding tor de markt (time-to-market).

De huidige standaard in de videorecordermarkt is de 1/2 inch A SD standiard. Hierbij stalat Standaard Definitic (SD) voor de kwaliteit van de beeldresolutie. 1/2 inch voor de breedte van de gebruikte band. terwijl $\mathrm{A}$ betekent dat analoge technologie wordt gebruikt voor de beeldopname. Er zijn ook zogenalande camcorders op de marki die $8 \mathrm{~mm}$ band gebruiken. maar dit type band wordt niet gebruikt in conventionele videospelers of de handzamere en kleinere personal videospelers. Philips produceert alle drie de types videospelers. maar alleen voor $1 / 2$ inch band toepassingen. Er wordt algemeen verondersteld dat - in samenhang met de trend tot miniaturisaltie - 8 m m band de uiteindelijke standaard wordt voor alle typen videospelers in de markt.
Philips moet een keuze maken tussen twee standaarden. analoog (8A SD) of digitaal (8D SD), wanneer de onderneming $8 \mathrm{~mm}$ producten voor de videomarkt galat ontwikkelen, walarbij beide standaarden worden gebascerd op dezelide nieuwe technologie. De analoge toepassing wordt hierbij ontwikkeld met behulp van elektromagnetische lechnologie, terwijl hij de digitale toepassing de beelden numeriek worden opgebouwd, hetgeen leidt tot een kwalitatief betere en scherpere beeldkwaliteit. Daarnaast is de digitale technologie minder gevoclig voor interferentie. vindt geen verlies aan beeldkwaliteit plaats en evenaart de geluidskwaliteit de verworvenheden van de Compact Disc (CD) technologie. Bij de digitale technologie is een type band benodigd dat gelijkenis vertoont met de band voor Digitale Compact Cassette (DCC) en dat anders is dan dat voor de analoge technologie. Beide technologieën kunnen worden benul voor de productie van de drie typen spelers: conventioneel. personal video en camcorders.

De keuze bestaat uit het verder ontwikielen van de huidige onderzoeks- en ontwikkelingsinspanningen ten behoeve van analoge (8A SD) videospelers of het starten met het volledige R\&D-traject voor de digitale productietechnologie (8D SD). Hicrbij draagt laatstgenoemde keuze het risico in zich dal consumenten nog niet open staan voor digitale videotechnologie. terwijl eerstgenoemde keuze het risico impliceert achterop te raken. terwijl de concurrentie de digitale videomarkt verovert.

De keuz van de ene technologie boven de andere kan vergaande gevolgen hebben voor de toekomstige markipositie in een sterk concurrerende markt. Vandaar dat de noodzalak om de productietechnologie te ontwikkelen voor de standaard die uileindelijk wereldwijd geacepteerd wordt. van essentieel belang is. Aanvankelijk hebben beide technologieën dezellde uitoefenprijs ten atanzien van vervolginvesteringen. omdat beide toepassingen op dezelide technologie gebaseerd worden. Echter. zij verschillen in verwachtingen omtrent toekomstige kasstromen en de beweeglijkheid van deze kasstromen. Analoge technologie wordt als minder risicovol gezien in vergelijking met digitale lechnologie die nog niel volledig is volgrocid. Hiertegenover statat dal consumenten miniaturisalie en digitalisering beschouwen als elementen vall een betere productkwaliteit. Daarnaast stijgt de verwachte 
groei voor de digitale videomarkt in belangrijke mate uit boven de groei van de analoge videomarkt. Toepassing van digitale technologie brengt echter wel hogere productiekosten met zich mee, omdat een duurdere soort band benodigd is. Omdat de technologie voor de analoge toepassing minder innovatief is, zijn de kosten van het ontwikkelen van de technologie voor digitale toepassing ook hoger dan de kosten van het ontwikkelen van de analoge technologie. Hieruit volgt dat het management bij de keuze voor één standaard zal kiezen voor de digitale standaard, omdat deze een hogere verwachte opbrengstwaarde heeft dan de analoge standaard. Het alternatief om uitsluitend de analoge standaard te ontwikkelen valt dus af. Hierdoor wordt de oorspronkelijke keuze uit vier alternatieven (de analoge en digitale standaard, alleen de analoge standaard, alleen de digitale standaard, of geen standaard te ontwikkelen) gereduceerd tot de beslissing om beide technologieën gelijktijdig te ontwikkelen, om uitsluitend de digitale technologie te ontwikkelen of om volledig af te zien van onderzoek en ontwikkeling voor deze videotechnologie.

\section{Optieanalyse van de R\&D-beslissing}

In de appendix is het door ons toegepaste model in verkorte geformaliseerde vorm gedefinieerd; voor een meer uitgebreide afleiding verwijzen wij naar Lint en Pennings (1996).

Met behulp van deze optiebenadering kan de beslissing omtrent de nadere ontwikkeling van analoge of digitale video gebaseerd op band geanalyseerd worden. Het is mogelijk een optie te creëren op beide standaarden en op deze wijze de definitieve keuze te verschuiven naar het moment van marktintroductie en zo de standaard te kiezen die het maximum aan kasstromen genereert. De onderliggende waarden van de optie bestaan uit de contante waarden op het moment van marktintroductie van de verwachte toekomstige kasstromen die verkregen worden met de introductie van de analoge, respectievelijk digitale productstandaard. Het creëren van de mogelijkheid impliceert het gelijktijdig ontwikkelen van beide standaarden en het ontwikkelen en vervaardigen van prototypes gebaseerd op beide standaarden. De kosten van het creëren van de mogelijkheid om beide standaarden gelijktijdig te ontwikkelen bestaan uit de extra kosten die gemoeid zijn met de volledige ontwikkeling van de digitale technologie in vergelijking met een verdere uitwerking van de analoge technologie. Het benutten van de mogelijkheid om beide standaarden te ontwikkelen is zinvol wanneer de nettowaarde van deze mogelijkheid - ofwel de optiewaarde op ontwikkeling van beide standaarden minus de kosten van het creëren van deze optie - groter is dan nul, alsmede groter is dan de netto-optiewaarde om uitsluitend $8 \mathrm{~A} \mathrm{SD}$ of uitsluitend 8D SD te ontwikkelen. Bij de optie op beide standaarden wordt de keuze van de definitieve standaard uitgesteld totdat de markt minder onzeker is, waardoor strategische flexibiliteit wordt verkregen.

Vervolgens bepalen wij het interval van de vervolginvesteringen $(X)$ in de productielijnen en marktintroductiekosten van de videospelers waarvoor geldt dat ontwikkeling van beide standaarden zinvol is. Door middel van 16 halfgestructureerde diepte-interviews met gesprekspartners van betrokken onderzoeks-, ontwikkelingsen marketingafdelingen, is informatie verkregen omtrent de invoergegevens voor ons model, onder andere de informatie omtrent de onzekerheid rond de contante waarde van iedere productstandaard alsmede de correlatie tussen beide contante waarden. Ieder interview omvat een kwantitatief gedeelte met 9 vragen omtrent toekomstige afzetprijzen, volumina, kostprijzen, de verwachte diffusiesnelheid van zowel 8A SD als ook 8D SD. alsmede de investeringen, marketinguitgaven en ontwikkelingskosten (loonkosten, apparatuur, etc.) voor het creëren van de drie alternatieven. Uit de gegevens van ieder afzonderlijk interview zijn de contante waarden berekend van de toekomstige opbrengsten van beide standaarden. Op deze wijze zijn de schattingen voor de onderliggende waarden verkregen. De uiteindelijke dataset die gebruikt is voor de schatting met behulp van de maximale aannemelijkheidsmethode (zie bijvoorbeeld Stewart, 1991) van de standaarddeviaties bestaat uit 32 waarnemingen.

Het is intuïtief duidelijk dat er twee tegengestelde effecten zijn met betrekking tot de correlatie van de contante waarde van de verwachte verkopen bij beide productstandaarden. Enerzijds zal een sterk groeiende markt voor digitale videoapparatuur een kannibaliserend effect hebben op de bestaande markt voor analoge videoproducten, hetgeen een negatieve correlatie suggereert. Anderzijds zijn beide toepassingen bestemd voor dezelfde markt, hetgeen een positieve correlatie 
impliceert. De correlatie blijkt dan ook een sleutelvariabele te zijn in hel oplossen van het keuzevraagstuk inzake de te ontwikkelen productstandaarden. Uit tabel I blijkt dat deze correlatie positief is, maar wel een relatief lage walarde heeft $(\rho=0.21$ ), hetgeen betekent dat beide technologieën in dezelfde richting worden beïnvloed door de verwachte acceptatiesnelheid en marktpenetralic, maar niet in dezelfde mate. Een lagere correlatiecoëfficient zou leiden tot een hogere payoff en resulteren in een hogere optiewaarde. Volgens verwachting is de standaarddeviatie van de onzekerheid rond de contante waarde van de digitale technologie groter dan de onzekerheid van de analoge toepassing.

Tabel 1: Schattingen met hehulp van maximale aammemelijkheid lan de standaarddeviaties en de correlatie met bijbehorende standaralfouten ulssen haken

\begin{tabular}{|c|c|}
\hline$\sigma_{A}$ & $0.21(0.03)$ \\
\hline$\sigma_{1}$ & $0.34(0.05)$ \\
\hline$\rho$ & $0.21(0.18)$ \\
\hline
\end{tabular}

De onderliggende waarden op het moment van marktintroductie worden gelijkgesteld aan de gemiddelde waarnemingen van de contante waarde van de toekomstige kasstromen voor beide technologieën. Omdat het optiemodel uitgaat van de huidige contante waarden moeten wij uiteindelijk deze waarden verdisconteren tegen de geldende vermogenskostenvoet. zijnde $13 \%$. Deze berekening resulteert in onderliggende waarden (op het huidige moment) voor de analoge productstandaard van $f 281 \mathrm{mln}$. en voor de digitale productstandaard van $f 411$ $\mathrm{mln}$. De risicovrije voet wordt gelijkgesteld aan het rendement op een staatsobligatie met dezelfde looptijd als de optie. zijnde $6 \%$. De tijd tussen het creëren van de optie en het uitoefenmoment bedraagt 3.5 jaar. De huidige contante waarde van de ontwikkelingskosten van alleen 8A SD en alleen 8D SD bedragen respektievelijk $f 40 \mathrm{mln}$. en $f 52 \mathrm{mln}$., terwijl de contante waarde van het gelijktijdig ontwikkelen van beide $f 68 \mathrm{mln}$. bedraagt: zie tabel 2. Omdat er synergetische voordelen bestaan bij de simultane ontwikkeling zijn de kosten van een gelijktijdige ontwikkeling lager dan de kosten van het ontwikkelen van iedere standiard op een individuele basis.
Tabel 2: Parameter watrden

\begin{tabular}{|c|c|}
\hline$S_{\lambda, 1}$ & Mfl 28l \\
\hline$S_{D, 1}$ & Mfl 4ll \\
\hline$r$ & 0.06 \\
\hline$\tau$ & 3.5 jaar \\
\hline$C_{A}$ & Mil 40 \\
\hline$C_{D}$ & Mfl 52 \\
\hline$C_{\text {AI }}$ & Mfl 68 \\
\hline
\end{tabular}

\section{Resultaten optieanalyse}

Met de waarden voor de verschillende parameters wordt in figuur I de netto-optiewaarde weergegeven. Dil is de optiewaarde van iedere mogelijke beslissing minus de kosten van het creëren van die optie als functic van de investeringen die benodigd zijn voor marktintroductie $(X)$. De horizontale lijn in de grafiek geeft de nullijn aan voor de nettowaarde. De optimale beslissing bestaat vervolgens uit de keuze van de mogelijkheid tot standaardisatie die de hoogste nettooptiewaarde geeft bij het relevante niveau van vervolginvesteringen. Deze keuzemogelijkheid is nihil wanneer er geen positieve netto-optiewaarde is voor een gegeven investeringsniveau in productiemiddelen en marktintroductie.

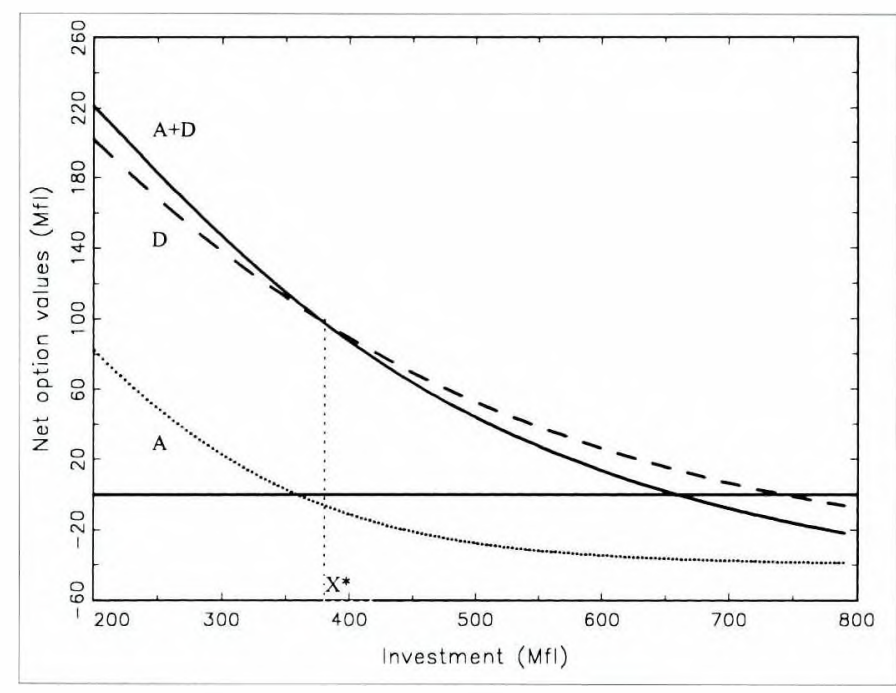

Figuar 1: Nettowande van de optie om analoge technologie te ontwikkelen (stippellijn), digitale technologie te ontwikkelen (streeplijn) en beide technologië̈n te ontwikkelen (doorgetrokken lijn). Bij een nitoefenprijs lager dan Mf7.380 is het ontwikkelen I'an beide technologieën optimaal; bij een aitoefenprijs hoger dan Mfl.380 doch lager dan Mfl.740 is het ontwikkelen van de digitale rechniek optimaal; bij een nitoefenprijs hoger alan M/7.740 moet afgezien worden wan ontwikkeling. 
Het interval in investeringen voor marktintroductie en productie waarvoor de optie op de gelijktijdige ontwikkeling van beide standaarden zinvol is, varieert van 0 tot ongeveer $f 380 \mathrm{mln}$. Op dit niveau $\left(X^{*}\right)$ zijn de nettowaarden van de optie om beide te ontwikkelen en de waarde van de optie om alleen de digitale standaard te ontwikkelen gelijk. In het interval $f 380 \mathrm{mln}$. tot $f 740$ $\mathrm{mln}$. moet de digitale standaard ontwikkeld worden. Wanneer $X$ vervolgens uitstijgt boven $f 740 \mathrm{mln}$., dan bedraagt geen enkele nettooptiewaarde meer dan 0 en suggereert de optieanalyse om bij een dergelijk hoog niveau van vervolginvesteringen volledig af te zien van de ontwikkeling van een nieuwe videostandaard.

\section{Conclusies en richtingen voor vervolgonderzoek}

De weergegeven analyse is afkomstig van een studie bij het Philipsconcern om de flexibiliteitswaarde te bepalen bij een standaardisatievraagstuk in de markt voor videoapparatuur. Uit onze case-beschrijving volgt dat Philips de keuze heeft tussen twee standaarden. analoog en digitaal, met betrekking tot $8 \mathrm{~mm}$ producten voor videoapparatuur met dezelfde hoogte van benodigde vervolginvesteringen. maar met verschillende verwachte kasstromen en risico`s. Uit de analyse blijkt dat de twee productstandaarden een lage positieve correlatie hebben. Ondat de extra kosten gemoeid met het simultaan ontwikkelen van nieuwe analoge technologie en digitale technologie relatief beperkt zijn, laten wij zien dat het al de moeite waard is om beide standaarden te ontwikkelen bij een relatief laag niveau van vervolginvesteringen. Zodra het niveau van vervolginvesteringen toeneemt, geeft het ontwikkelen van alleen de digitale technologie het hoogste nettoresultaat.

De modelbenadering veronderstelt dat de investeringen in productie en marketing die voor een succesvolle marktintroductie benodigd zijn. gelijk zijn voor beide standaarden. Omdat beide productstandaarden op dezelfde basistechnologie gebaseerd zijn, mag redelijkerwijs verondersteld worden dat in beide situaties de productiefaciliteiten identieke kapitaalsinvesteringen vergen.

Daarnaast neemt Philips een afwachtende houding aan, gegeven de veronderstelde afwezigheid van marktdominantie, alsmede de afwezigheid van een sterke octrooipositie in digitale tape recording. Derhalve mogen ook de marketinguitgaven voor de productintroductie van de uiteindelijk gekozen standaard voor beide applicaties redelijkerwijs gelijk worden gesteld. Voor meer uitgebreide toepassingen van het model zullen dergelijke veronderstellingen in de praktijk geen stand houden en moeten verschillende uitoefenprijzen voor de ontwikkelde standaarden in de analyse kunnen worden meegenomen. Voorzover ons bekend ontbreekt een dergelijke modelbenadering in de financieringstheorie en dit onderwerp verdient dan ook nader onderzoek.

Een ander belangwekkend aspect voor nader onderzoek wordt gevormd door onze veronderstelling dat het standaardisatievraagstuk rond digitale tape recording niet door het management te beïnvloeden is. Zoals aangegeven is deze veronderstelling te beargumenteren onder de marktomstandigheden voor Philips bij dit specifieke standaardisatievraagstuk. Echter, de managementpraktijk moet, gegeven de hedendaagse gevechten om een dominante productstandaard, ook voorzien worden van modelbenaderingen die optieanalyse integreren met speltheoretische inzichten, omdat in vele situaties de betrokken ondernemingen tenminste tot op zekere hoogte - over de mogelijkheid beschikken om de uitkomst van een standaardisatiestrijd te beïnvloeden; zie ook Smit (1996). De ondernemingsleiding moet hiertoe ondersteund worden met modellen die analytisch een waardering mogelijk maken van de simultane ontwikkeling van meerdere productstandaarden in samenhang met onzekere en onderling samenhangende verwachte payoffs van concurrenten. Tevens moeten de modellen inzicht geven in de dynamiek en fasering van onderling gerelateerde strategieën van de betrokken ondernemingen; een stevige uitdaging voor de wetenschap op dit terrein.

\section{I T E R A T U U R}

Baldwin, C.Y. en K.B. Clark, (1997), Modularity in Design: An Analysis Based on the Theory of Real Options, interne publicatie, Harvard Business School.

Dixit, A.K. en R.S. Pindyck, (1994), Investment under Uncertainty, Princeton, NJ: Princeton University Press.

Johnson, H.E., (1987), 'Options on the Maximum or the Minimum of Several Assets', Journal of Financial and Quantitative Analysis 22 (3), pp. 277-284.

Kemna, A.Z.G., (1988), 'Financiële en Reële Opties Gewaar- 
deerd', Maandblad voor Accountancy en Bedriffseconomie 62 (nr. 6), pp. 264-275.

Kester, W.C., (1984), 'Today's Options for Tomorrow's

Growth,' Harvard Business Review 62 (maart-april), pp. 153-160.

Lint, L.J.O. en H.P.G. Pennings, (1996), The Option Value of Developing Two Product Standards Simultaneously when the Final Standard is Uncertain, interne publicatie, Erasmus Universiteit Rotterdam.

Lint, L.J.O. en H.P.G. Pennings, (1998), 'De Recent overeengekomen digitale videostandaard. Een Speltheoretische Analyse. Deel I en II', te verschijnen in Bedrijtskunde. Myers, S.C., (1984), 'Finance Theory and Financial Strategy,' Interfaces 14 (januari-februari), pp. 126-137.

Sanchez, R.A., (1991), Strategic Flexibility, Real Options and Product-Based Strategy, proefschrift, MIT, Cambridge MA.

Sanderson, S. en M. Uzumeri, (1995), 'Managing Product Families: The Case of the Sony Walkman', Research Policy 24 (september), pp. 761-782.

Smit, J.T.J., (1996), Growth Options and Strategy Analysis, proefschrift, Universiteit van Amsterdam.

Stewart, J., (1991), Econometrics, New York, NY: Allan.

Stulz, R.M., (1982), 'Options on the Minimum or the Maximum of Two Risky Assets: Analysis and Applications', Journal of Financial Economics 10 (juli), pp. 161-185

Trigeorgis, L., (1996), Real Options, Cambridge, MA: MIT Press.

\section{Appendix}

De waarde van de optie om beide technologieën te ontwikkelen. $V_{\mathrm{AD}}$, wordt gegeven door

$V_{A D}=\exp (-r \tau) E\left[\operatorname{Max}\left[\operatorname{Max}\left(S_{, \gamma}, S_{D, r}\right)-X\right] .0\right]$

walubij $\mathrm{S}_{\mathrm{A}}$ en $\mathrm{S}_{\mathrm{D}}$ twee gecorreleerde geometrische Brownse bewegingen volgen met de risicovrije rente $(r)$ als groeivoet en een standaarddeviatie van respectievelijk $\sigma_{A}$ en $\sigma_{1}$. De veronderstelling van geometrische Brownse bewegingen is standaard in de reële optieliteratuur; zie Dixit en Pindyck (1994) in het algemeen en Baldwin en Clark (1997) voor een toepassing in de sfeer van productontwerpen. De symbolen $E$ en $\tau$ geven respectievelijk de verwachtingswaarde van de payoff in een risiconeutrale wereld en de looptijd van de optie weer. Stulz (1982) heeft bewezen dat $V_{A D}$ kan worden herschreven als

$V\left(S_{A, H}, S_{D, H}, X, \tau\right)=c\left(S_{A, r}, X, \tau\right)+c\left(S_{D,}, X, \tau\right)-M\left(S_{A, H} S_{D, n}, X, \tau\right)$

waar c $\left(S_{i, t}, X, l\right)$ een Europese call optie op $S_{\mathrm{i}}$ met uitoefenprijs $\mathrm{X}$ en een looptijd van $\tau$ jaar weergeeft en $M\left(S_{A,}, S_{D}, X, \tau\right)$ de waarde is van een Europese call optie op het minimum van $S_{\Lambda}$ en $S_{1}$. Deze waarde kan vervolgens geschreven worden als

$M\left(S_{1,1}, S_{D, 1}, X, \tau\right)$

$=S_{A, N_{2}} N_{2}\left(d_{A}+\sigma_{A} V \tau_{1}\left(\ln \left(S_{D, \ell} / S_{1,1}\right)-\sigma^{2} \tau\right) / \sigma V \tau_{.}\left(\rho \sigma_{D}\right)^{-}\left(\sigma_{1}\right) / \sigma\right)$

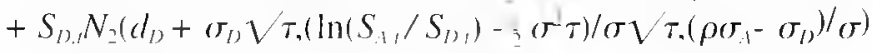

$-X e^{r T} N_{2}\left(d_{1}, d_{1}, \rho\right)$

net

$c\left(S_{i, r}, X, \tau=S_{i, i} N_{1}\left(d_{1}+\sigma_{1} l^{\prime} \tau\right)-X e^{-r \tau} N_{1}\left(d_{1}\right) \quad i=A, D\right.$

Met $N_{2}\left(\mathrm{~d}_{\lambda}, \mathrm{d}_{\mathrm{D}}, \rho\right)$ wordt de cumulatieve bivariate standaardnormale dichtheidsfunctie alangeduid warar $\mathrm{d}_{\lambda}$ en $\mathrm{d}_{1}$, de bovengrenzen van de integratie aanduiden en $\rho$ de correlatie weergeeft. $N_{1}(\gamma)$ is de cumulatieve standaardnormale dichtheidsfunctie met $\gamma$ als bovengrens van de integratie. Ten slotte kunnen $\mathrm{d}_{\wedge}$ en $\mathrm{d}_{1}$ geschreven worden als

$d_{i}=\left(\ln \left(S_{1} / X\right)+\left(r-\frac{1}{2}\left(\sigma_{1}\right) \tau\right) / \sigma_{1} \sqrt{\tau} \quad i=A, D\right.$

$\sigma^{\prime}=\sigma_{A}^{\prime}+\sigma_{D}-2 \rho \sigma_{A} \sigma_{D}$

Afsluitend is het voor de analyse in dit artikel van belang dat Siulz (1982) heeft aangetoond dat de partiële afgeleide van $V_{A D}$ nalar $\rho$ negatief is.

\section{Lijst van symbolen}

C A De contante waarde van de kosten om de analoge productstandaard te ontwikkelen.

$C_{D}$ De contante waarde van de kosten om de digitale productstandaard te ontwikkelen.

$C_{\text {N1 }}$ De contante waarde van de kosten om beide productstandaarden te ontwikkelen.

$r$ De risicovrije rentevoet.

$S_{A\lrcorner}$ De contante walarde van de kasstromen bij introduclie van de analoge slandaard.

$S_{D, t}$ De contante waarde van de kasstromen bij introductie van de digitale standarard.

$V_{A}$ De waarde van de optie om de analoge technologie te ontwikkelen.

$\mathrm{V}_{\mathrm{D}}$ De waarde van de optie om de digitale technologie te ontwikkelen.

$V_{\text {AI }}$ De walarde van de optie om beide technologieën te ontwikkelen.

$X$ De kosten van de irreversibele investering bij marktintroductie.

$X^{*}$ De waarde van $X$ warvoor $V_{A D}=V_{D}$.

$\rho$ De correlatie tussen de rendementen op $S_{A}$ en $S_{I}$.

$\sigma_{\mathrm{A}}$ De standaarddeviatie van het rendement op $\mathrm{S}_{\mathrm{A}}$.

$\sigma_{\mathrm{D}}$ De standaarddeviatie van het rendement op $\mathrm{S}_{\mathrm{D}}$.

$\tau$ De looptijd van de optie (de ontwikkelperiode). 